\title{
Increased breast cancer mortality only in the lower education group: age-period- cohort effect in breast cancer mortality by educational level in South Korea, 1983-2012
}

\author{
Jinwook Bahk ${ }^{1,3}$, Sung-Mi Jang ${ }^{2}$ and Kyunghee Jung-Choi ${ }^{2 *}$ (D)
}

\begin{abstract}
Background: A steadily increasing pattern of breast cancer mortality has been reported in South Korea since the late 1980s. This paper explored the trends of educational inequalities of female breast cancer mortality between 1983 and 2012 in Korea, and conducted age-period-cohort (APC) analysis by educational level.

Methods: Age-standardized mortality rates of breast cancer per 100,000 person-years were calculated. Relative index of inequality (RII) for breast cancer mortality was used as an inequality measure. APC analyses were conducted using the Web tool for APC analysis provided by the Division of Cancer Epidemiology and Genetics at the U.S. National Cancer Institute.

Results: An increasing trend in breast cancer mortality among Korean women between 1983 and 2012 was due to the increased mortality of the lower education groups (i.e., no formal education or primary education and secondary education groups), not the highest education group. The breast cancer mortality was higher in women with a tertiary education than in women with no education or a primary education during 1983-1992, and the reverse was true in 1993-2012. Consequently, RIl was changed from positive to negative associations in the early 2000s. The lower education groups had the increased breast cancer mortality and significant cohort and period effects between 1983 and 2012, whereas the highest group did not.

Conclusions: APC analysis by socioeconomic position used in this study could provide an important clue for the causes on breast cancer mortality. The long-term monitoring of socioeconomic patterning in breast cancer risk factors is urgently needed.
\end{abstract}

Keywords: Breast cancer, Socioeconomic inequality, Age-period-cohort effect, Korea

\section{Background}

Breast cancer was the leading cause of cancer death and the most commonly diagnosed cancer among women worldwide in 2012 [1]. In South Korea (hereafter 'Korea'), breast cancer was the second most diagnosed cancer following thyroid cancer, and the sixth fatal cancer for

\footnotetext{
* Correspondence: jungchoikh@gmail.com

${ }^{2}$ Department of Occupational and Environmental Medicine, Ewha Womans University School of Medicine, 911-1 Mok-6-dong, Yangchun-gu, Seoul 158-710, South Korea

Full list of author information is available at the end of the article
}

women in 2012 [2]. While decreasing patterns of breast cancer mortality rates were found in western countries since the 1990s, a steadily increasing pattern of breast cancer mortality has been reported in Korea since the late 1980s [3].

Breast cancer was viewed as a "cancer of affluence" because the incidence and mortality of breast cancer was positively related to high socioeconomic position and more developed countries [4,5]. Although the positive relationship between breast cancer mortality and socioeconomic position has still been observed frequently [6], 
breast cancer mortality among the low socioeconomic groups has been catching up with the high socioeconomic groups [7]. Several recent studies reported negative or no association between breast cancer mortality and socioeconomic position [8-11]. Among those, the change of inequality direction on breast cancer mortality in Korea was most prominent. Educational inequalities of breast cancer mortality were changed from a significant positive association in 2001 to a significant negative association in 2011, and this trend was first observed in younger women $[9,12]$.

Age-period-cohort (APC) effect analysis can provide clues of the cause of the disease through describing temporal variations of disease incidence or mortality. APC effect on breast cancer has been analyzed in many studies including those done in Korea [13-16]. However, to the best of our knowledge, there has been no study analyzing APC effect considering socioeconomic position. Especially in the situation where each socioeconomic position group has different trends like breast cancer mortality in Korea, APC effect analysis might supply more salient information.

In this study we examined the trends of educational inequalities of female breast cancer mortality between 1983 and 2012 in Korea, and conducted APC analysis by educational level.

\section{Methods}

\section{Data}

Female breast cancer (C500-C509 in International Classification of Disease-10) mortality data (death certificate data) from 1983 to 2012 and the National Census data in $1985,1990,1995,2000,2005$, and 2010 were obtained from Micro Data Service System provided by Statistics Korea (http://mdis.kostat.go.kr/). Female breast cancer mortality data were categorized into seven 5 -year age groups (25-29, 30-34, 35-39, .. 55-59), six 5-year calendar periods (1983-1987, 1988-1992, 1993-1997, 19982002, 2003-2007, 2008-2012), and three educational levels (no formal education or primary: 0-6 years, secondary: 7-12 years, tertiary: 13+). The National Census data were used as the denominators (numbers of women at risk) and categorized into seven 5-year age groups and three educational levels for each census year. The 5year birth cohort groups were defined by subtracting age from period based on the midpoint of the five-year age band and the mid-year of the five-year calendar period.

\section{Statistical analysis}

Age-standardized mortality rates of breast cancer per 100,000 person-years for each 5-year calendar period were calculated by the direct method with the 2005 Korean census population as the standard population. The breast cancer mortality rate ratio and 95\% confidence interval (95\% CI) for each 5-year calendar period was estimated using Poisson regression and adjusted for age. Relative index of inequality (RII) for breast cancer mortality was used as an inequality measure. To obtain RII, we ordered the educational groups from highest (tertiary) to lowest (no formal education or primary) and calculated the cumulative percentage distribution of each educational group by 5 -year age groups and 5-year calendar periods. Poisson regression model was used to estimate the RII. These analyses were performed using SAS software version 9.3 (SAS Institute, Cary, NC, USA).

APC analyses were conducted using the Web tool for APC analysis provided by Division of Cancer Epidemiology and Genetics at the U.S. National Cancer Institute (http://analysistools.nci.nih.gov/apc/). Additional details of the Web tool are described elsewhere [17]. From the Web tool, we obtained estimated annual percentage changes of the age-standardized rates (net drift), estimated age-specific annual percentage change over time (local drifts), ratio of longitudinal versus cross-sectional age curves, ratio of age-specific rates in each period relative to reference period 1993-1997 (period rate ratios), and ratio of age-specific rates in each cohort relative to reference cohort 1953 (cohort rate ratios). In all APC analyses, the reference groups were the central age group, central calendar period, and central birth cohort group. We created all figures using the $\mathrm{R}$ statistical programming language. Additionally, total number of female breast cancer deaths and person-years according to age groups, and age-specific mortality rate by educational level during1983-2012 were presented in Additional file 1: Table S1 and Additional file 2: Table S2.

\section{Results}

Figure 1 shows the age-standardized mortality rate of female breast cancer per 100,000 person-years according to educational level between 1983 and 2012 in Korea. The age-standardized mortality rate of breast cancer for all Korean women increased during the last three decades from 4.61 (95\% CI: $4.39-4.83$ ) to 8.22 (95\% CI: 8.00-8.43). Women with no formal education or a primary education and with a secondary education showed an increasing age-standardized mortality rate during study period, whereas women with a tertiary education had no consistent trend. Women with a tertiary education showed the highest mortality rate between 1983-1987 and 1988-1992, and then lower than women with no formal education or primary education (see Additional file 3: Table S3 for the detail numbers).

Table 1 presents the age-adjusted mortality rate ratio and RII for breast cancer mortality according to 5 year calendar periods. The risk of breast cancer death among women with no formal education or primary education 


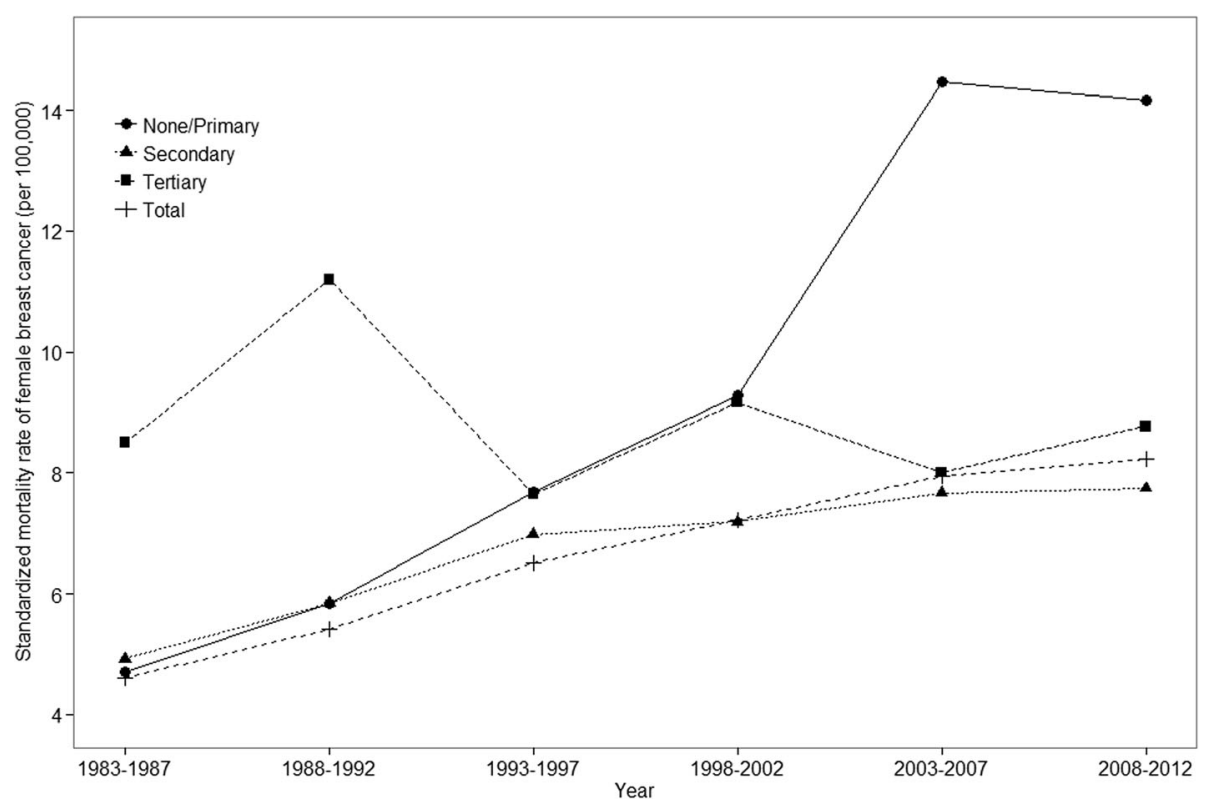

Fig. 1 Age-standardized (reference population = 2005 Korean census) mortality rate of breast cancer by educational level between 1983 and 2012 among Korean women

was 0.66 (95\% CI: 0.54-0.82) times compared to women with a tertiary education in 1983-1987, and that increased to 1.31 (95\% CI: 1.19-1.43) in 2008-2012. The RII for breast cancer mortality showed a significant increased trend across the full period ( $p$ value for trend $<0.0001$ ). The estimated RII for breast cancer mortality comparing the lowest with the highest education categories was 0.72 ( $95 \% \mathrm{CI}=0.60$ to 0.85$)$ in $1988-1992$ and $1.23(95 \% \mathrm{CI}=$ 1.10 to 1.36 ) in 2008-2012 (Table 1).

Table 2 shows the estimated annual percentage changes of the age-standardized breast cancer mortality rates and the estimated age-specific annual percentage change over time by educational level. Breast cancer mortality rates increased $3.85 \%$ annually among women with no formal education or primary education, while among women with a tertiary education it showed no significant annual change. Age-specific annual percentage change in the breast cancer mortality rates during the study periods showed significant positive value among women with no formal education or primary education and women with a secondary education aged between 30-34 and 55-59. No significant age-specific annual percentage change occurred among women with a tertiary education (Table 2).

Figure 2 presents the longitudinal age curves of female breast cancer mortality by educational level. The risks of breast cancer death increased in all education groups. The secondary education group (Fig. 2c) shows the lowest rate at all age groups, while the tertiary education group (Fig. 2d) shows the highest rate at ages 40-44 and thereafter (Fig. 2).

Figure 3 shows the estimated period effects by educational level. The no formal education or primary education group (Fig. 3b) shows an upward pattern during the study periods, while the tertiary education group (Fig. 3d)

Table 1 Age-adjusted mortality rate ratio and relative index of inequality for breast cancer mortality according to 5 year calendar periods

\begin{tabular}{|c|c|c|c|c|}
\hline & \multicolumn{3}{|l|}{ Rate ratio } & \multirow[t]{2}{*}{ RII } \\
\hline & None/Primary & Secondary & Tertiary & \\
\hline 1983-1987 & $0.66(0.54-0.82)$ & $0.67(0.54-0.82)$ & 1 (reference) & $0.84(0.68-1.03)$ \\
\hline 1988-1992 & $0.60(0.51-0.70)$ & $0.63(0.54-0.73)$ & 1 (reference) & $0.72(0.60-0.85)$ \\
\hline 1993-1997 & $0.96(0.84-1.10)$ & $1.03(0.91-1.16)$ & 1 (reference) & $0.92(0.80-1.07)$ \\
\hline 1998-2002 & $0.86(0.77-0.96)$ & $0.87(0.79-0.95)$ & 1 (reference) & $0.88(0.77-1.00)$ \\
\hline 2003-2007 & $1.38(1.25-1.52)$ & $1.05(0.97-1.13)$ & 1 (reference) & $1.45(1.29-1.63)$ \\
\hline 2008-2012 & $1.31(1.19-1.43)$ & $0.91(0.86-0.97)$ & 1 (reference) & $1.23(1.10-1.36)$ \\
\hline$p$ value for trend & & & & $<.0001$ \\
\hline
\end{tabular}


Table 2 Estimated annual percentage changes $(95 \% \mathrm{Cl})$ of the age-standardized breast cancer mortality rates and estimated agespecific annual percentage change ( $95 \%$ Cl) over time

\begin{tabular}{|c|c|c|c|c|}
\hline & \multirow[b]{2}{*}{ Total } & \multicolumn{3}{|l|}{ Educational level } \\
\hline & & None or primary & Secondary & Tertiary \\
\hline Net drift $(95 \% \mathrm{Cl})$ & $1.87(1.63-2.11)$ & $3.85(1.23-6.53)$ & $1.89(1.51-2.27)$ & $-0.34(-1.11-0.43)$ \\
\hline$p$-value & $<0.001$ & 0.004 & $<0.001$ & 0.386 \\
\hline \multicolumn{5}{|l|}{ Local drifts (95\% Cl) } \\
\hline $25-29$ & $-0.40(-1.35-0.55)$ & $-4.45(-20.42-14.72)$ & $1.35(-0.19-2.90)$ & $-0.29(-1.93-1.39)$ \\
\hline $30-34$ & $0.67(0.18-1.16)$ & $4.29(0.80-7.90)$ & $2.08(1.36-2.81)$ & $-0.14(-1.26-1.00)$ \\
\hline $35-39$ & $1.79(1.46-2.12)$ & $6.13(4.68-7.60)$ & $2.80(2.34-3.26)$ & $0.40(-0.59-1.40)$ \\
\hline $40-44$ & $1.82(1.54-2.09)$ & $5.75(4.97-6.54)$ & $1.92(1.53-2.32)$ & $0.09(-0.85-1.04)$ \\
\hline $45-49$ & $2.28(2.03-2.54)$ & $5.22(4.76-5.68)$ & $1.43(1.04-1.82)$ & $-0.36(-1.36-0.65)$ \\
\hline $50-54$ & $3.02(2.72-3.31)$ & $4.83(4.43-5.24)$ & $1.29(0.77-1.81)$ & $-1.14(-2.46-0.20)$ \\
\hline $55-59$ & $3.87(3.41-4.33)$ & $4.44(3.89-4.99)$ & $2.23(1.16-3.31)$ & $-0.99(-3.43-1.51)$ \\
\hline$p$-value & $<0.001$ & 0.001 & $<0.001$ & 0.272 \\
\hline
\end{tabular}

Net drift: Estimated annual percentage changes of the age-standardized rates

Local drifts: Estimated age-specific annual percentage change over time

shows no significant increase except 1988-1992 (Fig. 3). Additional file 4: Table S4 shows Wald tests results for period effects. Period effects were statistically significant for the no formal education or primary education group $(p=0.002)$ and the secondary education group $(p<0.0001)$ (Additional file 4: Table S4).

Figure 4 shows the estimated cohort effects by educational level. Women from the 1928 birth cohort to the 1973 birth cohort had increasing cohort effects on breast cancer mortality over time, especially among the no formal education or primary education group (Fig. 4b) and the secondary education group (Fig. 4c), while the tertiary education group (Fig. 4d) showed no significant increase (Fig. 4). Additional file 4: Table S4 shows Wald tests results for cohort effects. Cohort effects were statistically significant for the no formal education or primary education group $(p<0.0001)$ and the secondary education group $(p<0.0001)$ (Additional file 4: Table S4).

\section{Discussion}

This study showed that an increasing trend in breast cancer mortality among Korean women between 1983 and 2012 was due to the increased mortality of the lower education groups (i.e., no formal education or primary education and secondary education groups), not the highest education group. The breast cancer mortality was higher in women with a tertiary education than in women with no education or a primary education during 1983-1992, and the reverse was true in 1993-2012. Consequently, RII was changed from positive to negative associations in the early 2000s. We also found significant cohort and period effects in the lower education groups, while cohort and period effects were not observed in the highest education group.
Breast cancer has been one of the well-known diseases with a positive social gradient $[6,18,19]$. Although no significant associations were observed in some countries $[11,20]$, most western countries have a consistent positive association by education in breast cancer mortality [6] This study showed educational inequality for breast cancer mortality before the early 2000s in Korea also had a positive association like most western countries. However, after the early 2000s, the RII for breast cancer mortality was changed to a negative association, which was mainly related to the rapid increase in breast cancer mortality of the lowest education group for the last 30 years.

The change of the inequality pattern could be explained by the changes of the incidence, survival, and risk factors across education groups. Breast cancer incidence among Korean women increased during 19932012 [2, 21]. However, the changing patterns between the incidence of breast cancer and socioeconomic position were observed during these periods. According to Korean hospital-based studies, women with a low educational level had a significantly lower incidence of breast cancer in 1994 [22], while women with a high educational level had a significantly lower incidence in 2004 [23]. In addition, a national level study showed that breast cancer incidence inequality which was presented as RII by household income was not significant in 2001 [24]. Based on these studies, we can assume that the incidence of breast cancer might be changed from less favorable to more favorable for the higher education group during the last decades, which could be one factor that led the change of breast cancer mortality inequality by educational level.

Furthermore, socioeconomic breast cancer mortality disparities could be partially explained by the risk factors 

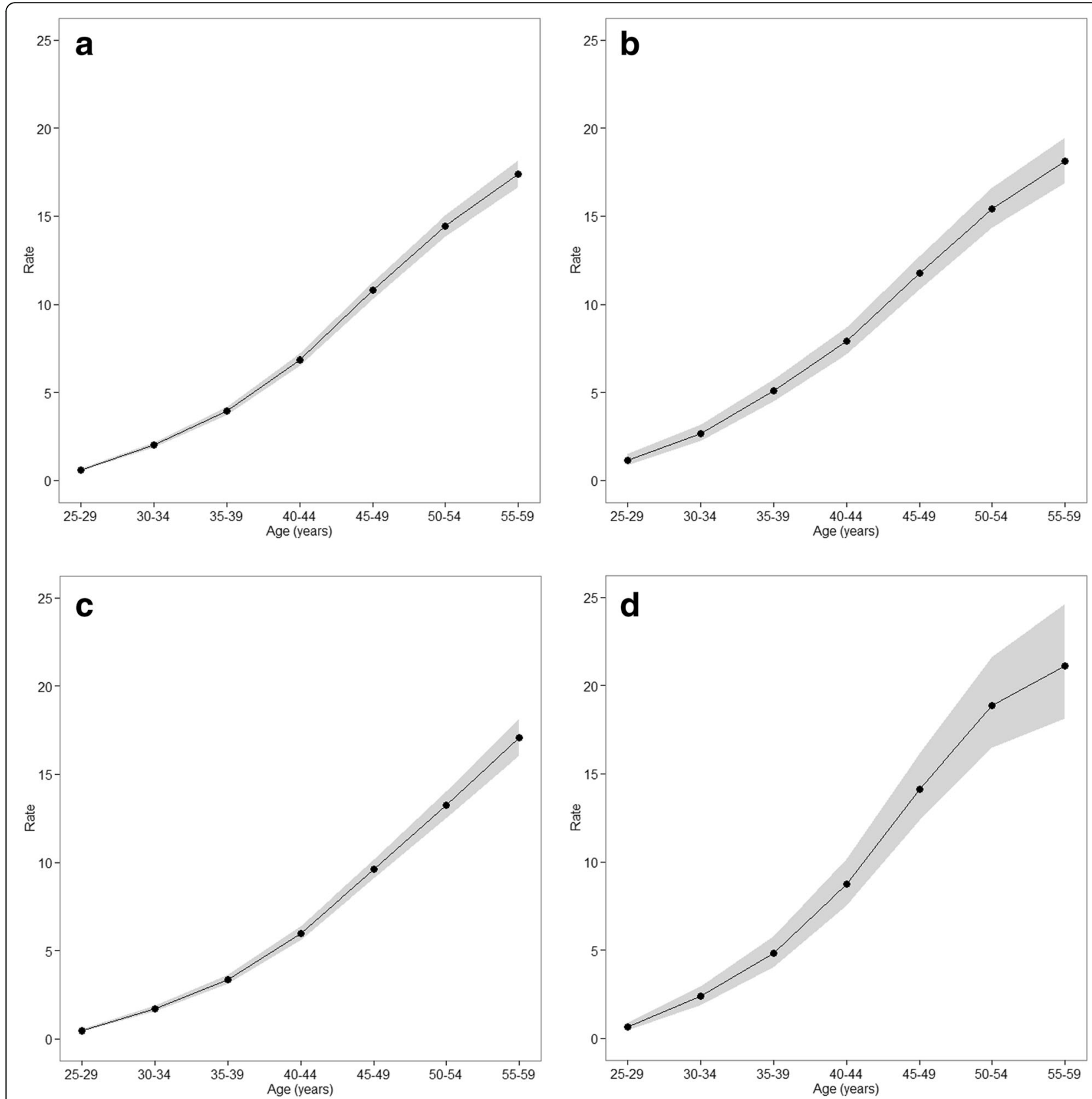

Fig. 2 Longitudinal age curves of female breast cancer mortality by educational level; Expected age-specific rates in reference cohort c0 adjusted for period effects $\mathbf{a}$ total, $\mathbf{b}$ none or primary, $\mathbf{c}$ secondary, $\mathbf{d}$ tertiary

related to the survival rate such as screening, tumor stage distribution at diagnosis, and treatment inequalities [25]. The National Cancer Screening Program for breast cancer was started in 1999 in Korea [26]. This program provided free cancer screening for the medical aid beneficiary group at first, and extended gradually to the national health insurance beneficiaries in the bottom $50 \%$ of income in 2006. Despite this program, women with a low socioeconomic position were less likely to attend the screening program $[27,28]$, and the trend of inequality in screening attendance did not decrease between 1998 and 2012 [29]. Thus, women with a low socioeconomic position were more likely to have had a delayed diagnosis and significantly worse tumor stage [30, 31]. After diagnosis, women with a low socioeconomic position were less likely to have had optimal treatment [32], and thus less likely to survive [33]. Nonetheless, it should be noted that inequality of survival factors could contribute to the increase of breast cancer mortality inequality, but that could not explain 

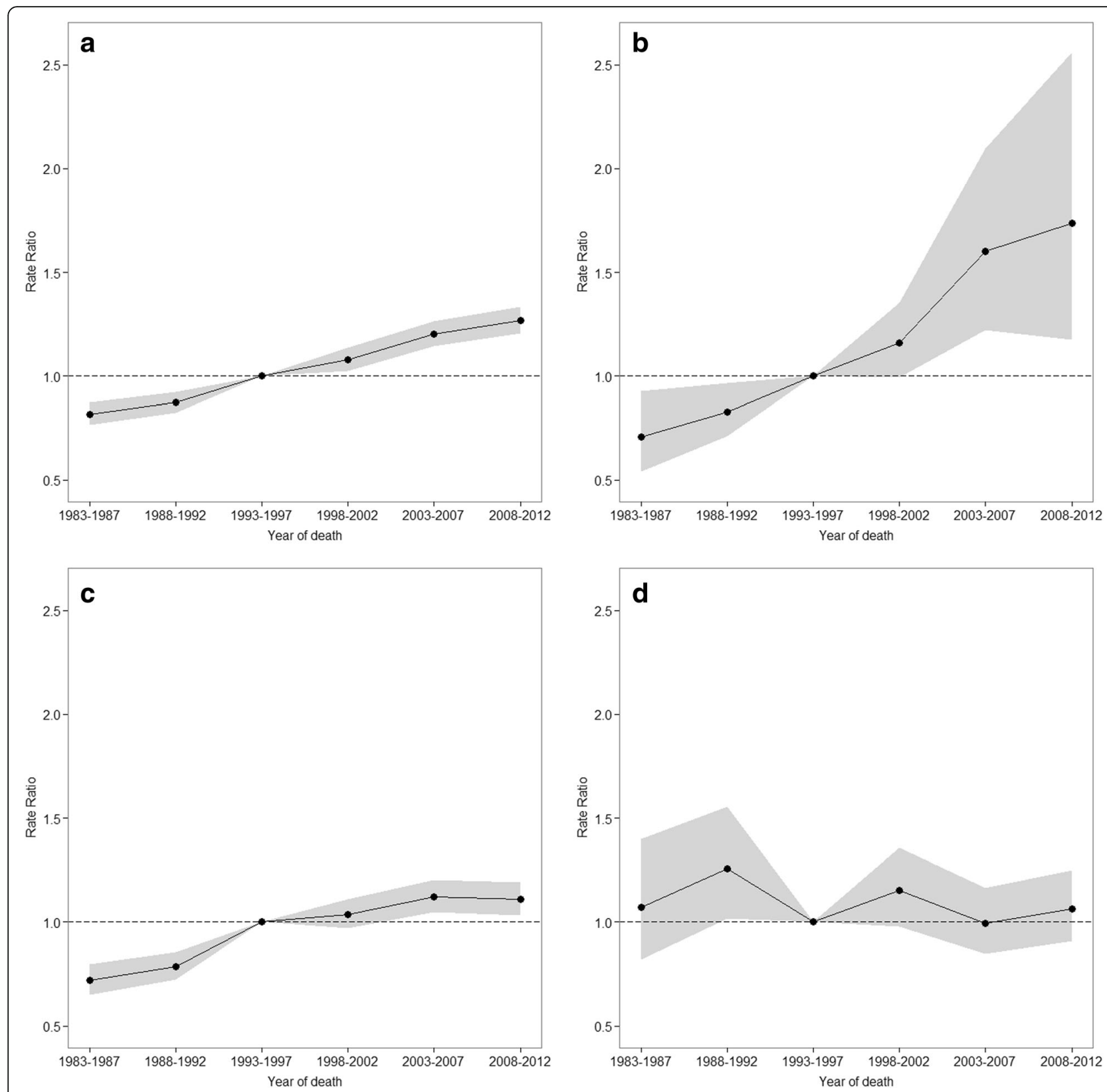

Fig. 3 Period rate ratios by educational level: the period relative risk adjusted for age and non-linear cohort effects in each period relative to reference period 1993-1997; a total, b none or primary, c secondary, $\mathbf{d}$ tertiary

the increase of breast cancer mortality itself in the lower education group because survival rates from breast cancer in Korea have increased consistently [2, 34].

In addition, several risk factors might have contributed to the mortality disadvantages among the less educated. For example, the prevalence of obesity in Korea was higher in the lower education group and the inequality for abdominal obesity by educational group increased between 1998 and 2007 [35]. The rate of oral contraceptive use of the lower education group was higher than that of the highest education group in 2005 [36]. Those factors could have attributed to the increase of breast cancer mortality in the lower education group. However, considering the incubation period from the exposure to the risk factors to the occurrence of cancer, those results with a limited time period seemed to lack the necessary evidence to explain the unique increase of breast cancer mortality in the lower education group.

Analysis results showed that the lower education groups had the increased breast cancer mortality and significant cohort and period effects between 1983 and 2012, whereas the highest group did not. The risk factors 

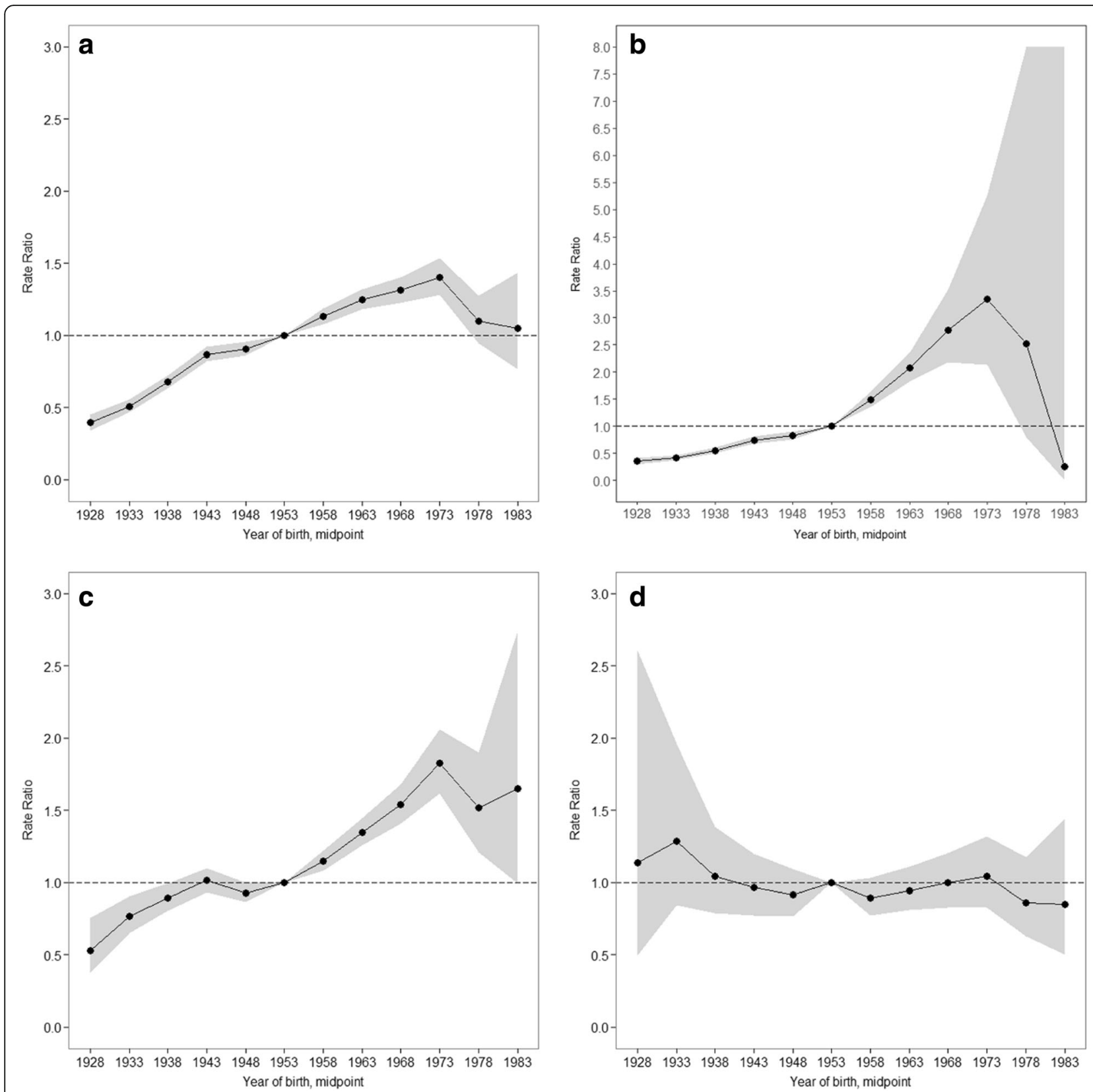

Fig. 4 Cohort rate ratios by educational level: the cohort relative risk adjusted for age and non-linear period effects in each cohort relative to reference cohort 1953; a total, b none or primary, c secondary, d tertiary

which could accompany the cohort effects in breast cancer incidence are reproductive factors (e.g., early menarche, late menopause, delayed age at first birth, and less breastfeeding) and behavioural factors (e.g., high fat diet, obesity, alcohol use, and use of exogenous hormone) [37]. Behavioural factors could be related to the predominant lifestyle and food and drug supply of the time period, and could produce the period effect as well. Most above risk factors were suggested as explanations for the increasing cohort effects on breast cancer mortality in the previous studies, because the prevalence of the risk factors also has increased with economic development and westernization of lifestyle in Korea [14, 37].

This study also showed that women with a lower education had higher breast cancer death rates in more current cohorts in contrast to the highest education group. It means that if the risk factors with the different pattern of the prevalence by educational level were found, it would be reasonable that those factors were considered as main risk factors for the increase of breast cancer mortality. However, unfortunately, there were few studies that contained evidence to conclude what the 
main risk factors were. Reproductive factors including age at first birth were still less favorable for the higher education group in Korea [38], likewise with western countries $[39,40]$, and the study which supported the decreasing gap in reproductive factors between educational groups could not be found. The gap of age at first birth by educational level among the 1960-1964 birth cohort, the 1965-1969 birth cohort, and the 1970-1974 birth cohort was not different [41], although the gap of the number of live births by educational level decreased between 1980 and 2000 [42].

This study has limitations. First, this study is ecological, thereby we can only speculate on the etiologies of the observed changes. Second, population distribution of educational attainment among Korean women changed dramatically during 1983 to 2012. Only 6.2\% of women attained a tertiary education during 1983-1987. The percentage increased to $38.9 \%$ in $2008-2012$, while women with no or a primary education only accounted for $7.2 \%$ in 2008-2012 (see Additional file 1: Table S1 for the population distribution of educational attainment). Large standard errors, which should be interpreted with caution, resulted from the fact that the highest education group in the 1980s and the lowest education group in the 2000s had the small number of deaths, despite our having used figures for total population and deaths.

On the other hand, this study has an important strength in that, to the best of our knowledge, this is the first study to analyze the APC effects on female breast cancer mortality by educational level over 30 years. APC analysis by socioeconomic position could be applied to explore the causes of other diseases with epidemiologic transition.

\section{Conclusions}

In conclusion, this study showed that the lower education groups had the increased breast cancer mortality and significant cohort and period effects between 1983 and 2012, whereas the highest group did not. This approach could provide an important clue for the cause on the trend of breast cancer mortality. Considering the increasing mortality of breast cancer and the widening gap in breast cancer mortality between the high and low education groups, the long-term monitoring of socioeconomic patterning in breast cancer risk factors are urgently needed.

\section{Additional files}

Additional file 1: Table S1. Total number of female breast cance death and person-years according to age groups, and \% person years for educational groups during1983-2012 in Korea. (DOCX 14 kb)

Additional file 2: Table S2. Age-specific mortality rate per 100,000 person-years during1983-2012 in Korea. (DOCX 14 kb)
Additional file 3: Table S3. Age-standardized (reference population = 2005 census) mortality rate of breast cancer by educational level among Korean women according to 5 year calendar periods between 1983 and 2012. (DOCX 13 kb)

Additional file 4: Table S4. Rate ratios ( $95 \% \mathrm{Cl}$ ) of periods and cohorts by educational level. (DOCX $14 \mathrm{~kb}$ )

\section{Abbreviations}

APC: Age-period-cohort; RIl: Relative index of inequality

Acknowledgements

Not applicable

Availability of data and materials

All data were publicly available on the website of the Statistics Korea (http://mdis.kostat.go.kr/)

\section{Funding}

This research was supported by Basic Science Research Program through the National Research Foundation of Korea (NRF) funded by the Ministry of Science, ICT \& Future Planning (2014R1A1A1008250).

\section{Authors' contributions}

KJC designed the study and collected the data. JB performed the statistical analysis. JB, SMJ, and KJC drafted and critically revised the manuscript. All authors read and approved the final paper.

\section{Competing interests}

The authors declare that they have no competing interests

\section{Consent for publication}

Not applicable

\section{Ethics approval and consent to participate}

This study was approved by the Ewha Medical Center Institutional Review Board, Seoul, Korea (ECT 14-24B-04 [2014.07.30]). Consent to participate was not required, as this study did not involve human participant interactions and all data were publicly available and de-identified.

\section{Publisher's Note}

Springer Nature remains neutral with regard to jurisdictional claims in published maps and institutional affiliations.

\section{Author details}

${ }^{1}$ Department of Public Health, Keimyung University, 1095 Dalgubeol-Daero, Dalseo-Gu, Daegu 42601, South Korea. ${ }^{2}$ Department of Occupational and Environmental Medicine, Ewha Womans University School of Medicine, 911-1 Mok-6-dong, Yangchun-gu, Seoul 158-710, South Korea. ${ }^{3}$ Institute of Health Policy and Management, Seoul National University Medical Research Center, 103 Daehak-ro, Jongno-gu, Seoul 110-799, South Korea.

Received: 18 November 2016 Accepted: 27 March 2017

Published online: 31 March 2017

References

1. IARC. World Cancer Report 2014. Lyon: International Agency for Research on Cancer; 2014.

2. Jung KW, Won YJ, Kong HJ, Oh CM, Cho H, Lee DH, et al. Cancer statistics in Korea: incidence, mortality, survival, and prevalence in 2012. Cancer Res Treat. 2015:47(2):127-41. doi:10.4143/crt.2015.060.

3. GLOBOCAN 2012: Estimated Incidence, Mortality and Prevalence Worldwide in 2012. Available from: Available at http://globocan.iarc.fr/Pages/fact_ sheets_cancer.aspx Accessed: 30 Dec 2015

4. McPherson K, Steel CM, Dixon JM. ABC of breast diseases. Breast cancerepidemiology, risk factors, and genetics. BMJ. 2000;321(7261):624-8.

5. Rimpela AH, Pukkala El. Cancers of affluence: positive social class gradient and rising incidence trend in some cancer forms. Soc Sci Med. 1987;24(7):601-6.

6. Strand BH, Kunst A, Huisman M, Menvielle G, Glickman M, Bopp M, et al. The reversed social gradient: higher breast cancer mortality in the higher 
educated compared to lower educated. A comparison of 11 European populations during the 1990s. Eur J Cancer. 2007;43(7):1200-7. doi:10.1016/j. ejca.2007.01.021.

7. Krieger N. Is breast cancer a disease of affluence, poverty, or both? The case of African American women. Am J Public Health. 2002;92(4):611-3.

8. Albano JD, Ward E, Jemal A, Anderson R, Cokkinides VE, Murray T, et al. Cancer mortality in the United States by education level and race. J Natl Cancer Inst. 2007;99(18):1384-94. doi:10.1093/jnci/djm127.

9. Kim MH, Jung-Choi K, Kim H, Song YM. Educational inequality in female cancer mortality in Korea. J Korean Med Sci. 2015;30(1):1-6. doi:10.3346/ jkms.2015.30.1.1.

10. Martikainen $P$, Valkonen T. Diminishing educational differences in breast cancer mortality among Finnish women: a register-based 25-year follow-up. Am J Public Health. 2000;90(2):277-80.

11. Menvielle G, Rey G, Jougla E, Luce D. Diverging trends in educational inequalities in cancer mortality between men and women in the 2000s in France. BMC Public Health. 2013;13:823. doi:10.1186/1471-2458-13-823.

12. Jung-Choi $\mathrm{K}$, Khang $\mathrm{YH}$, Cho HJ. Changes in contribution of causes of death to socioeconomic mortality inequalities in Korean adults. J Prev Med Public Health. 2011;44(6):249-59. doi:10.3961/jpmph.2011.44.6.249.

13. Chia KS, Reilly M, Tan CS, Lee J, Pawitan Y, Adami HO, et al. Profound changes in breast cancer incidence may reflect changes into a Westernized lifestyle: a comparative population-based study in Singapore and Sweden. Int J Cancer. 2005;113(2):302-6. doi:10.1002/ijc.20561.

14. Choi Y, Kim Y, Park SK, Shin HR, Yoo KY. Age-Period-Cohort Analysis of Female Breast Cancer Mortality in Korea. Cancer research and treatment. 2015. doi:10.4143/crt.2015.021

15. Hermon C, Beral V. Breast cancer mortality rates are levelling off or beginning to decline in many western countries: analysis of time trends, age-cohort and age-period models of breast cancer mortality in 20 countries. Br J Cancer. 1996;73(7):955-60.

16. Wang Z, Bao J, Yu C, Wang J, Li C. Secular trends of breast cancer in China, South Korea, Japan and the United States: application of the age-periodcohort analysis. Int J Environ Res Public Health. 2015;12(12):15409-18. doi:10. 3390/ijerph121214993.

17. Rosenberg PS, Check DP, Anderson WF. A Web Tool for Age-Period-Cohort Analysis of Cancer Incidence and Mortality Rates. Cancer Epidem Biomar. 2014:23(11):2296-302. doi:10.1158/1055-9965.Epi-14-0300.

18. Carlsen K, Hoybye MT, Dalton SO, Tjonneland A. Social inequality and incidence of and survival from breast cancer in a population-based study in Denmark, 1994-2003. Eur J Cancer. 2008:44(14):1996-2002. doi:10.1016/j.ejca. 2008.06.027.

19. Fujino Y, Mori M, Tamakoshi A, Sakauchi F, Suzuki S, Wakai K, et al. A prospective study of educational background and breast cancer among Japanese women. Cancer Causes Control. 2008;19(9):931-7. doi:10.1007/ s10552-008-9154-5.

20. Larsen SB, Kroman N, Ibfelt EH, Christensen J, Tjonneland A, Dalton SO. Influence of metabolic indicators, smoking, alcohol and socioeconomic position on mortality after breast cancer. Acta Oncol. 2015;54(5):780-8. doi: 10.3109/0284186x.2014.998774.

21. Lee JH, Yim SH, Won YJ, Jung KW, Son BH, Lee HD, et al. Population-based breast cancer statistics in Korea during 1993-2002: incidence, mortality, and survival. J Korean Med Sci. 2007:22(Suppl):S11-6.

22. Suh JS, Yoo KY, Kwon OJ, Yun IJ, Han SH, Noh DY, et al. Menstrual and reproductive factors related to the risk of breast cancer in Korea. Ovarian hormone effect on breast cancer. J Korean Med Sci. 1996;11(6):501-8.

23. Lee EO, Ahn SH, You C, Lee DS, Han W, Choe KJ, et al. Determining the main risk factors and high-risk groups of breast cancer using a predictive model for breast cancer risk assessment in South Korea. Cancer Nurs. 2004:27(5):400-6.

24. Kim CW, Lee SY, Moon OR. Inequalities in cancer incidence and mortality across income groups and policy implications in South Korea. Public health. 2008;122(3):229-36. doi:10.1016/j.puhe.2007.07.003.

25. Woods LM, Rachet B, Coleman MP. Origins of socio-economic inequalities in cancer survival: a review. Ann Oncol. 2006;17(1):5-19. doi:10.1093/annonc/ mdj007.

26. Park EC, Kwak MS, Lee JY, Choi KS, Shin HR. The Present and Challenges of National Cancer Screeing Program. Korean J Health Promot. 2005;3(2):280-7.

27. Lee K, Lim HT, Park SM. Factors associated with use of breast cancer screening services by women aged $>$ or $=40$ years in Korea: the third Korea National Health and Nutrition Examination Survey 2005 (KNHANES III). BMC Cancer. 2010;10:144. doi:10.1186/1471-2407-10-144.
28. Park MJ, Park EC, Choi KS, Jun JK, Lee HY. Sociodemographic gradients in breast and cervical cancer screening in Korea: the Korean National Cancer Screening Survey (KNCSS) 2005-2009. BMC Cancer. 2011;11:257. doi:10.1186/ 1471-2407-11-257.

29. Kim S, Kwon S, Subramanian SV. Has the national cancer screening program reduced income inequalities in screening attendance in South Korea? Cancer Causes Control. 2015;26(11):1617-25. doi:10.1007/s10552-015-0655-8.

30. Jung HM, Lee JS, Lairson DR, Kim $Y$. The effect of national cancer screening on disparity reduction in cancer stage at diagnosis by income level. Plos One. 2015;10(8):e0136036. doi:10.1371/journal.pone.0136036.

31. Lyratzopoulos G, Abel GA, Brown CH, Rous BA, Vernon SA, Roland M, et al. Socio-demographic inequalities in stage of cancer diagnosis: evidence from patients with female breast, lung, colon, rectal, prostate, renal, bladder, melanoma, ovarian and endometrial cancer. Ann Oncol. 2013;24(3):843-50. doi:10.1093/annonc/mds526.

32. Yoon TH, Lee SY, Kim CW, Kim SY, Jeong BG, Park HK. Inequalities in medical care utilization by South Korean cancer patients according to income: a retrospective cohort study. Int J Health Serv. 2011;41(1):51-66.

33. Herndon 2nd JE, Kornblith AB, Holland JC, Paskett ED. Effect of socioeconomic status as measured by education level on survival in breast cancer clinical trials. Psychooncology. 2013;22(2):315-23. doi:10.1002/pon.2094.

34. Moon EK, Park HJ, Oh CM, Jung KW, Shin HY, Park BK, et al. Cancer incidence and survival among adolescents and young adults in Korea. Plos One. 2014;9(5):e96088 doi:10.1371/journal.pone.0096088.

35. Yoo S, Cho HJ, Khang YH. General and abdominal obesity in South Korea, 1998-2007: gender and socioeconomic differences. Prev Med. 2010;51(6): 460-5. doi:10.1016/j.ypmed.2010.10.004.

36. Jang S. Population Attributable Fraction of Breast Cancer Risk Factors by Education Status (Doctoral dissertation). Seoul: Ewha Womans University; 2015.

37. Yoo KY, Kang D, Park SK, Kim SU, Shin A, Yoon H, et al. Epidemiology of breast cancer in Korea: Occurrence, high-risk groups, and prevention. J Korean Med Sci. 2002;17(1):1-6.

38. Sung J, Song YM. The relationship between education level and mammographic density. Eur J Cancer Prev. 2015;24(6):491-6. doi:10.1097/cej. 0000000000000120

39. Menvielle G, Kunst AE, van Gils $\mathrm{CH}$, Peeters PH, Boshuizen $H$, Overvad K, et al. The contribution of risk factors to the higher incidence of invasive and in situ breast cancers in women with higher levels of education in the European prospective investigation into cancer and nutrition. Am J Epidemiol. 2011;173(1):26-37. doi:10.1093/aje/kwq319.

40. Strand BH, Tverdal A, Claussen B, Zahl PH. Is birth history the key to highly educated women's higher breast cancer mortality? A follow-up study of 500,000 women aged 35-54. Int J Cancer. 2005;117(6):1002-6. doi:10.1002/ ijc.21239.

41. Choi K. Empirical Analysis on the Causes of Korea's Fertility Drop. Seoul: Korea Development Institute; 2008.

42. Kim TH, Lee SS, Kim DH. Fertility differentials by demographic and socioeconomic characteristics: analysis of korean population census data. Korea J Popul Stud. 2006;29(1):1-23.

\section{Submit your next manuscript to BioMed Central and we will help you at every step:}

- We accept pre-submission inquiries

- Our selector tool helps you to find the most relevant journal

- We provide round the clock customer support

- Convenient online submission

- Thorough peer review

- Inclusion in PubMed and all major indexing services

- Maximum visibility for your research

Submit your manuscript at www.biomedcentral.com/submit 